\title{
Meet women's health needs with postabortion care
}

Frontiers in Reproductive Health

Follow this and additional works at: https://knowledgecommons.popcouncil.org/departments_sbsr-rh

Part of the International Public Health Commons, and the Women's Health Commons How does access to this work benefit you? Let us know!

\section{Recommended Citation}

"Meet women's health needs with postabortion care," Program Brief Summary. Washington, DC:

Population Council, 2000. 


\section{Meet Women's Health Needs With Postabortion Care}

W orldwide, one in eight pregnancyrelated deaths result from complications of unsafe abortion such as bleeding, infection or internal injuries. Many of these deaths could be prevented if women had the means to avoid unplanned pregnancy. At the 1994 United Nations International Conference on Population and Development, 180 governments identified postabortion care (PAC) as a high-priority public health issue. As part of the resulting global PAC initiative, the Population Council and other international organizations collaborated with governments and non-governmental organizations in a worldwide program of operations research on interventions to improve postabortion care. This summary highlights the major findings of this research.

\section{PAC: A Comprehensive Care Strategy}

Failure to plan systematic treatment for abortion complications often leads to lowquality services and inefficient use of health care resources, including staff time and facilities. By adopting more systematic, comprehensive protocols for postabortion care, health program managers can improve the quality of services and reduce overall costs.

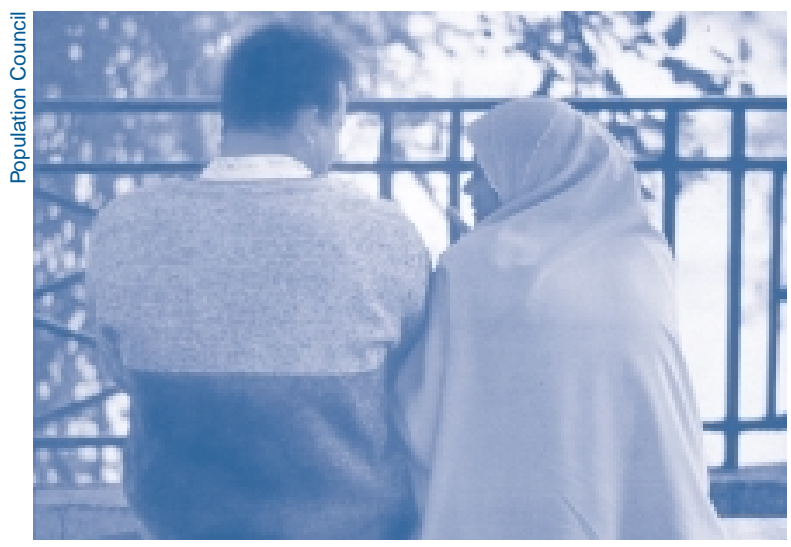

PAC is a service delivery strategy built around three elements:

- Emergency treatment of medical complications of spontaneous or induced abortion

\section{- Postabortion family planning counseling, services and referral}

- Links to other reproductive health services, such as diagnosis and treatment of reproductive tract infections

By offering family planning counseling and services, PAC helps to prevent repeat abortions.

\section{Five Steps to Improving Postabortion Care}

\section{Improve clinical care.}

- Use emergency treatment techniques appropriate to the setting and the patient. - Provide appropriate pain management before, during, and after the clinical procedure.

- Adhere to infection prevention protocols.

- Ensure availability of adequate supplies of essential medications and necessary equipment.

- Improve provider interactions with patients.

Summary of: Meeting Women's Health Care Needs after Abortion, by Dale Huntington. Program Brief. 1. Washington, D.C.: Population Council/FRONTIERS, 2000. 


\section{Figure 1. \\ Proportion of PAC Clients Counseled Who Obtained a Contraceptive Method}

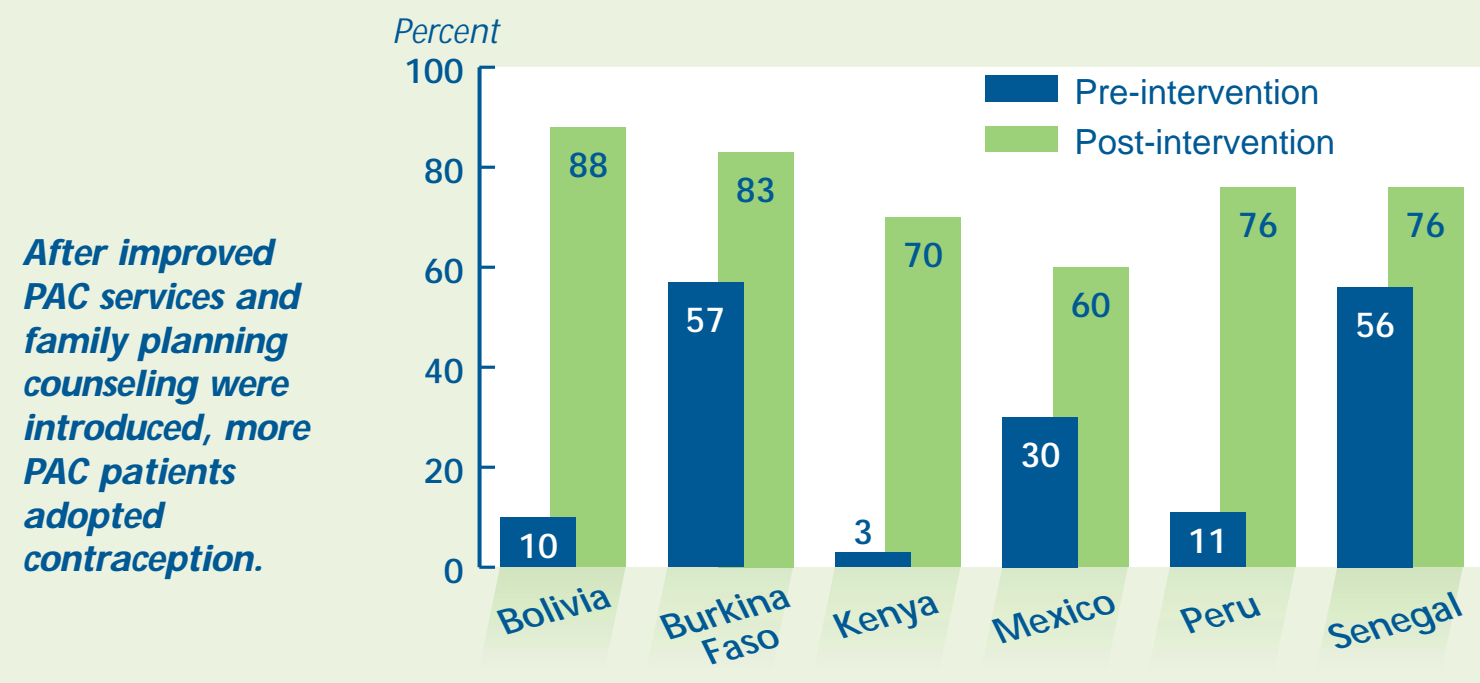

\section{Provide family planning counseling and services.}

- Inform patients about the rapid return of fertility following abortion.

- Offer family planning counseling and services to postabortion patients before discharge from the treatment facility.

\section{Expand access to PAC.}

- Establish PAC services closer to where the need exists, at lower-level facilities where appropriate.

- Train health workers to provide family planning counseling and services and make referrals for other reproductive health services. In some settings, mid-level practitioners can provide emergency treatment for incomplete abortion.

- Ensure that community health workers will refer women to emergency obstetric care.

\section{Plan comprehensive PAC services.}

- Plan PAC as a routine element of obstetric and gynecological care.

- Consolidate treatment and counseling in one service area to increase efficiency. - Offer outpatient PAC services, especially treatment of incomplete abortion.

\section{Involve male partners.}

- Inform male partners about PAC treatment and follow-up care, with the woman's prior consent.

PAC offers a holistic approach that can improve the quality of services, meet women's reproductive health needs more effectively, and decrease the cost of care. PAC services are a key component of reproductive health programs and make an important contribution to women's overall health and well-being.
Frontiers in Reproductive Health

Population Council

4301 Connecticut Ave., N.W., Suite 280

Washington, D.C. 20008

U.S.A.
Tel.: 202-237-9400

Fax: 202-237-8410

E-mail: frontiers@pcdc.org

www.popcouncil.org
This publication was made possible through support provided by the Office of Population, Bureau for Global Programs, Field Support and Research, U.S. AGENCY FOR INTERNATIONAL DEVELOPMENT (USAID), under the terms of Cooperative Agreement No. HRN-A00-98-00012. The opinions expressed herein do not necessarily reflect the views of USAID. 